2. Muder RR, Yu VL, Fang GD. Community-acquired Legionnaires' disease. Semin Respir Infect. 1989;4:32-9.

3. Fields BS, Benson RF, Besser RE. Legionella and Legionnaires' disease: 25 years of investigation. Clin Microbiol Rev. 2002;15:506-26. https://doi.org/10.1128/ CMR.15.3.506-526.2002

4. Centers for Disease Control and Prevention. Guidance for reopening buildings after prolonged shutdown or reduced operation; 2019 [cited 2020 Jul 19]. https:/ / www.cdc.gov/ coronavirus/2019-ncov/php/building-water-system.html

5. ESCMID Study Group for Legionella Infections. ESGLI Guidance for managing Legionella in building water systems during the COVID-19 pandemic. 2020 [cited 2020 Dec 15]. https:/ / www.pwtag.org/esgli-guidance-managinglegionella-building-water-systems-covid-19-pandemic

6. Arashiro T, Nakamura S, Asami T, Mikuni H, Fujiwara E, Sakamoto S, et al. SARS-CoV-2 and legionella co-infection in a person returning from a Nile cruise. J Travel Med. 2020;27:taaa053. https://doi.org/10.1093/jtm/taaa053

7. Rota MC, Fontana S, Montaño-Remacha C, Scaturro M, Caporali MG, Vullo V, et al. Legionnaires' disease pseudoepidemic due to falsely positive urine antigen test results. J Clin Microbiol. 2014;52:2279-80. https:/ / doi.org/ 10.1128/JCM.00493-14

8. Pierre DM, Baron J, Yu VL, Stout JE. Diagnostic testing for Legionnaires' disease. Ann Clin Microbiol Antimicrob. 2017;16:59. https:// doi.org/10.1186/s12941-017-0229-6

9. Kohler RB, Winn WC Jr, Wheat LJ. Onset and duration of urinary antigen excretion in Legionnaires disease. J Clin Microbiol. 1984;20:605-7. https:/ / doi.org/10.1128/ JCM.20.4.605-607.1984

10. Dionne M, Hatchette T, Forward K. Clinical utility of a Legionella pneumophila urinary antigen test in a large university teaching hospital. Can J Infect Dis. 2003;14:85-8. https://doi.org/10.1155/2003/642159

Address for correspondence: Hedda Luise Verhasselt, Institute of Medical Microbiology, University Hospital Essen, Virchowstr 179, 45147 Essen, Germany; email: hedda-luise.verhasselt@uk-essen.de

\section{Temporal Variations in Respiratory Syncytial Virus Epidemics, by Virus Subtype, 4 Countries}

\author{
Lisa Staadegaard, Adam Meijer, \\ Ana Paula Rodrigues, Sue Huang, Cheryl Cohen, \\ Clarisse Demont, Jojanneke van Summeren, \\ Saverio Caini, John Paget
}

Author affiliations: Netherlands Institute for Health Services Research (Nivel), Utrecht, the Netherlands (L. Staadegaard, J. van Summeren, S. Caini, J. Paget); National Institute for Public Health and the Environment (RIVM), Bilthoven, the Netherlands (A. Meijer); Instituto Nacional de Saúde Doutor Ricardo Jorge, Lisbon, Portugal (A.P. Rodrigues); Institute of Environmental Science and Research Limited, Upper Hutt, New Zealand (S. Huang); National Institute for Communicable Diseases, Johannesburg, South Africa (C. Cohen); University of Witwatersrand, Johannesburg (C. Cohen); Sanofi Pasteur, Lyon, France (C. Demont)

DOI: https://doi.org/10.3201/eid2705.204615

Temporal variation of respiratory syncytial virus (RSV) epidemics was recently reported to be determined by the dominant RSV subtype. However, when we repeated the analysis for 4 countries in the Northern and Southern Hemispheres, the dominant subtype did not seem to affect temporal variation of RSV epidemics.

$\mathrm{R}$ espiratory syncytial virus (RSV) is responsible for most acute lower respiratory tract infections in young children worldwide (1) and accounts for a substantial burden among older adults (2). Although it is generally accepted that RSV epidemics in temperate climates occur in winter, some temporal variation epidemics remains unexplained (3).

Recently, $\mathrm{Yu}$ et al. conducted a study among children ( $<13$ years of age) with pneumonia at the Beijing Children's Hospital (Beijing, China) during July 2007-June 2015 and reported that temporal variation is partly explained by seasonal differences in virus subtype dominance (4). To define the timing of RSV seasonality, they used a regression model and 10\% threshold method previously described (3). They found that onset and peak of seasons occurred $\approx 3-5$ weeks earlier and that duration was $\approx 6$ weeks longer when RSV subtype A (RSV-A) was dominant than when subtype B (RSV-B) was dominant. These results, if generalizable, would have major implications for the 
epidemiology of RSV surveillance programs and healthcare planning.

We examined whether similar patterns in the dominant RSV subtype and timing of RSV epidemics were found in the Northern and Southern Hemispheres by using a large dataset from the Global Epidemiology of RSV in the Community and Hospitalised Care study (https://www.nivel.nl/en/ geri). We included in our analysis only countries with a temperate climate. For Northern Hemisphere countries, seasons were defined as week 27 through week 26 of the next calendar year; for Southern Hemisphere countries, seasons were defined as week 1 through 52 of the same calendar year. We included seasons if $\geq 50$ RSV cases with subtyped information available (diagnosed by PCR) had been reported. We included persons of all ages; the Beijing study included only children $<13$ years of age. In addition, the case definitions for each study did not entirely overlap. In defining the start, duration, and peak of the RSV seasons, we followed a similar approach as $\mathrm{Yu}$ et al. (i.e., $10 \%$ threshold [4]). We defined the onset week of an epidemic as the first of 2 consecutive weeks in which the percentage of specimens testing positive exceeded $10 \%$. The offset week was determined as the second week of the last 2 consecutive weeks when this threshold was breached (3).

We explored the relationship between the timing of an epidemic and the dominant RSV subtype $(>50 \%$ of cases) by calculating the mean start, end, and duration of the seasons according to virus subtype. We applied a regression analysis with robust SEs to account for the potential clustering of individual country results.

We included weekly subtyped RSV data from the Northern (Netherlands and Portugal) and Southern (New Zealand and South Africa) Hemispheres; surveillance systems for those countries are described elsewhere (5-8). We analyzed 24 seasons $(5,189$ cases), of which RSV-A was dominant for 14 (Table). A dominant RSV-A or RSV-B season was determined by using the $50 \%$ cutoff; this percentage was frequently close to $50 \%$. For example, the proportion of persons with an RSV-A-positive test result was $51 \%-85 \%$ (Figure). All differences in timing were not significant;

\begin{tabular}{|c|c|c|c|c|c|c|c|c|}
\hline Location, season & $\begin{array}{c}\text { Start, } \\
\text { calendar wk }\end{array}$ & $\begin{array}{c}\text { End, } \\
\text { calendar wk }\end{array}$ & $\begin{array}{c}\text { Duration, } \\
\text { wk }\end{array}$ & $\begin{array}{c}\text { Peak, } \\
\text { calendar wk }\end{array}$ & $\begin{array}{c}\text { No. } \\
\text { cases }\end{array}$ & $\begin{array}{c}\text { No. subtyped } \\
\text { cases }\end{array}$ & $\begin{array}{c}\text { Subtype } \\
\text { A, } \%\end{array}$ & $\begin{array}{c}\text { Dominant } \\
\text { subtype }\end{array}$ \\
\hline \multicolumn{9}{|c|}{ Northern Hemisphere } \\
\hline \multicolumn{9}{|c|}{ The Netherlands } \\
\hline 2009-10 & 49 & 8 & 12 & 3 & 100 & 100 & 44 & $\mathrm{~B}$ \\
\hline 2010-11 & 4 & 7 & 4 & 6 & 82 & 82 & 68 & A \\
\hline 2011-12 & 51 & 4 & 6 & 51 & 53 & 53 & 36 & $\mathrm{~B}$ \\
\hline 2012-13 & 51 & 5 & 7 & 2 & 60 & 60 & 75 & A \\
\hline 2013-14 & 3 & 8 & 6 & 4 & 72 & 72 & 44 & $\mathrm{~B}$ \\
\hline 2014-15 & 6 & 13 & 8 & 9 & 73 & 73 & 37 & $\mathrm{~B}$ \\
\hline 2015-16 & 51 & 5 & 7 & 2 & 110 & 110 & 35 & $\mathrm{~B}$ \\
\hline 2016-17 & 47 & 2 & 8 & 51 & 123 & 123 & 70 & A \\
\hline 2017-18 & 47 & 52 & 7 & 51 & 75 & 75 & 17 & B \\
\hline Average & 52 & 6 & 7 & 3 & 83 & 83 & 47 & $\mathrm{~B}$ \\
\hline \multicolumn{9}{|l|}{ Portugal } \\
\hline $2012-13$ & 50 & 1 & 4 & 50 & 94 & 80 & 78 & A \\
\hline 2013-14 & 52 & 3 & 4 & 52 & 298 & 103 & 70 & A \\
\hline 2014-15 & 44 & 18 & 27 & 51 & 412 & 38 & 13 & B \\
\hline 2015-16 & 47 & 13 & 19 & 51 & 646 & 99 & 63 & A \\
\hline $2016-17$ & 45 & 12 & 20 & 4 & 682 & 91 & 55 & A \\
\hline 2017-18 & 44 & 15 & 24 & 5 & 1,084 & 142 & 51 & A \\
\hline 2018-19 & 44 & 18 & 27 & 10 & 1,662 & 101 & 27 & B \\
\hline Average & 47 & 11 & 18 & 2 & 697 & 93 & 51 & A \\
\hline \multicolumn{9}{|c|}{ Southern Hemisphere } \\
\hline \multicolumn{9}{|c|}{ New Zealand } \\
\hline 2012 & 18 & 37 & 20 & 26 & 880 & 152 & 85 & A \\
\hline 2013 & 15 & 32 & 18 & 27 & 1,238 & 367 & 21 & B \\
\hline 2014 & 24 & 34 & 11 & 27 & 1,406 & 409 & 65 & A \\
\hline 2015 & 13 & 32 & 20 & 24 & 1,430 & 295 & 58 & A \\
\hline 2016 & 12 & 32 & 21 & 26 & 1,020 & 185 & 66 & A \\
\hline Average & 16 & 33 & 18 & 26 & 1,195 & 282 & 52 & A \\
\hline \multicolumn{9}{|l|}{ South Africa } \\
\hline 2016 & 8 & 28 & 21 & 17 & 750 & 675 & 59 & A \\
\hline 2017 & 7 & 30 & 24 & 16 & 848 & 825 & 33 & B \\
\hline 2018 & 6 & 26 & 21 & 15 & 922 & 879 & 60 & A \\
\hline Average & 7 & 28 & 22 & 16 & 840 & 793 & 51 & A \\
\hline
\end{tabular}



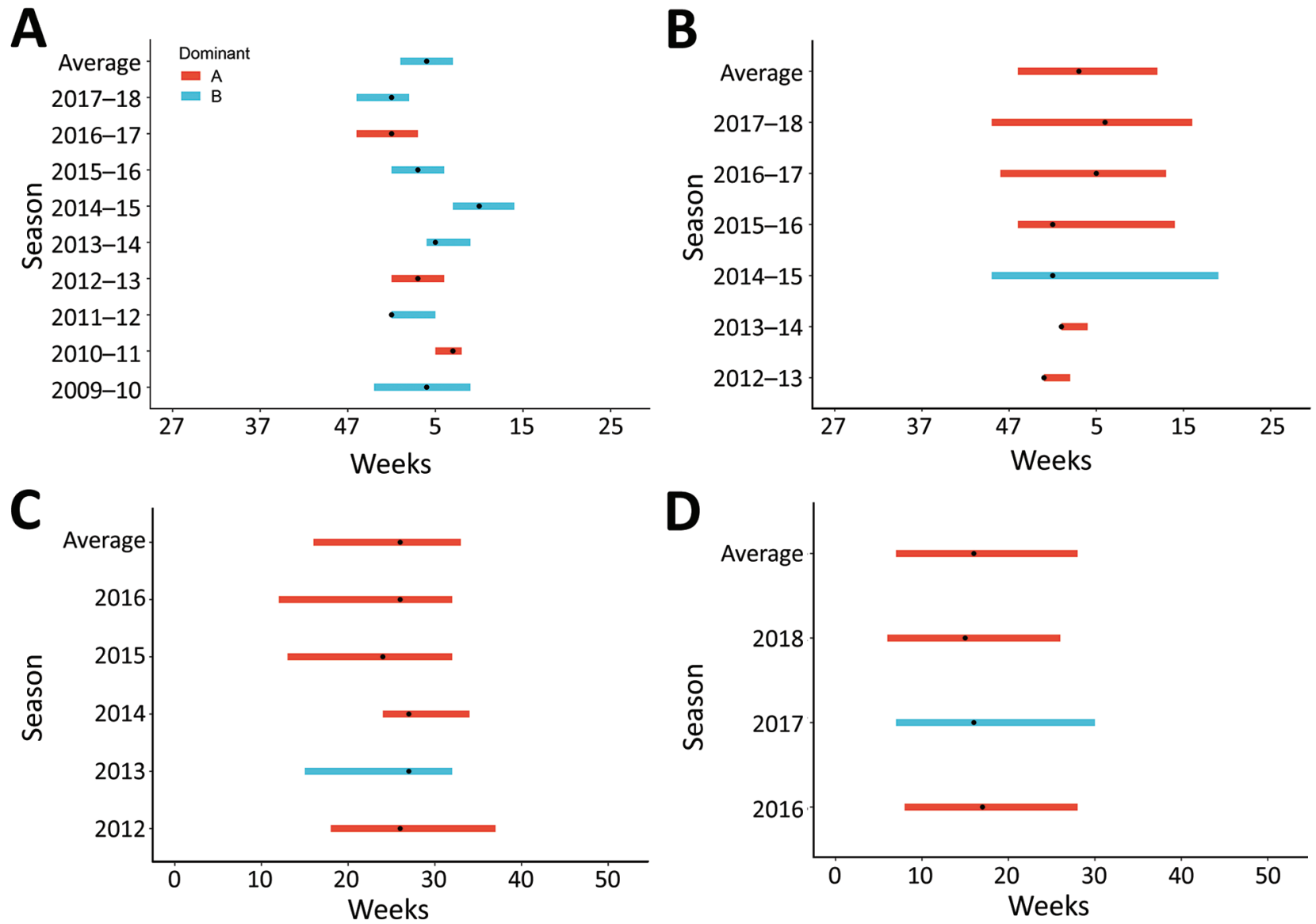

Figure. Temporal variation in respiratory syncytial virus, defined by using $10 \%$ positivity threshold, by dominant virus subtype, country, and season. A) The Netherlands; B) Portugal; C) New Zealand; D) South Africa. Black dots indicate the peak (highest percentage of cases testing positive) of the season.

RSV-A-dominant seasons started 2 weeks earlier ( $\mathrm{p}$ $=0.3)$, ended 2 weeks earlier $(p=0.3)$, and peaked 2 weeks earlier $(p=0.2)$ than RSV-B-dominant seasons. Mean durations were 14.5 weeks for RSV-A-dominant seasons and 14.9 weeks for RSV-B-dominant seasons $(p=0.9)$.

We found no significant difference in the effect of the dominant RSV subtype on temporal variation of RSV epidemics. We did not find the earlier start and longer duration of RSV-A-dominant seasons described by $\mathrm{Yu}$ et al. when we used similar methods for the countries included in our analysis. Although the national datasets and dataset used by Yu et al. differ from those that we used in several ways (e.g., case definition and age categories), we believe that these differences do not preclude conducting temporal comparisons of this type.

One limitation of our analysis and that of $\mathrm{Yu}$ et al. is the definition of a dominant season. Small differences in virus subtype distribution potentially have a major effect on the results, especially when case numbers are lower in included seasons. An example is the 2016-17 season in Portugal, when RSVA prevailed but was responsible for only 142 (51\%) cases. That finding was similar to that described by Yu et al. for the 2013-14 season, which experienced an almost equal number of cases caused by RSV-A $(\mathrm{n}=35)$ and RSV-B $(\mathrm{n}=33)$. This limitation substantially reduces conclusions that can be drawn from this type of analysis, and we advocate a more stringent definition of an RSV dominant subtype per season (e.g., $>70 \%$ threshold) for future analyses, thereby ensuring that differences in subtype distribution are real. We recommend that countries monitor RSV subtypes so that our findings can be validated with more data because a temporal variation in RSV epidemics caused by this subtype would have a major effect on the epidemiology of RSV, surveillance programs, and healthcare planning at the local level. 


\section{Acknowledgments}

We thank Anne Teirlinck, Gé Donker, Mariëtte Hooiveld, Janneke Hendriksen, the general practitioners, and the patients who contributed to the virologic part of the national sentinel surveillance for influenza-like illness and acute respiratory infection. We also thank Peter Spreeuwenberg for his statistical advice.

This study was funded by Sanofi Pasteur and AstraZeneca.

L.S., A.M., A.P.R., S.H., C.C., J.S., and S.C. declare no competing interests. J.P. declares that Nivel has received unrestricted research grants from the World Health Organization, Sanofi Pasteur, and the Foundation for Influenza Epidemiology. C.D. is an employee of Sanofi Pasteur and may hold shares or stock options in the company.

\section{About the Author}

Ms. Staadegaard is an epidemiologist working at the Netherlands Institute for Health Services Research in the Netherlands. Her main research interests include the epidemiology of infectious diseases, with a current focus on respiratory infections.

\section{References}

1. Shi T, McAllister DA, O'Brien KL, Simoes EAF, Madhi SA, Gessner BD, et al.; RSV Global Epidemiology Network. Global, regional, and national disease burden estimates of acute lower respiratory infections due to respiratory syncytial virus in young children in 2015: a systematic review and modelling study. Lancet. 2017;390:946-58. https:/ / doi.org/10.1016/S0140-6736(17)30938-8

2. Shi T, Denouel A, Tietjen AK, Campbell I, Moran E, Li X, et al. Global disease burden estimates of respiratory syncytial virus-associated acute respiratory infection in older adults in 2015: a systematic review and meta-analysis. J Infect Dis. 2020;222:S577-83.

3. Haynes AK, Prill MM, Iwane MK, Gerber SI; Centers for Disease Control and Prevention (CDC). Respiratory syncytial virus - United States, July 2012-June 2014. MMWR Morb Mortal Wkly Rep. 2014;63:1133-6.

4. Yu J, Liu C, Xiao Y, Xiang Z, Zhou H, Chen L, et al. Respiratory syncytial virus seasonality, Beijing, China, 20072015. Emerg Infect Dis. 2019;25:1127-35. https://doi.org/ 10.3201/eid2506.180532

5. Vos LM, Teirlinck AC, Lozano JE, Vega T, Donker GA, Hoepelman AI, et al. Use of the moving epidemic method (MEM) to assess national surveillance data for respiratory syncytial virus (RSV) in the Netherlands, 2005 to 2017. Euro Surveill. 2019;24. https://doi.org/10.2807/1560-7917. ES.2019.24.20.1800469

6. Sáez-López E, Pechirra P, Costa I, Cristóvão P, Conde P, Machado A, et al. Performance of surveillance case definitions for respiratory syncytial virus infections through the sentinel influenza surveillance system, Portugal, 2010 to 2018. Euro Surveill. 2019;24. https://doi.org/10.2807/ 1560-7917.ES.2019.24.45.1900140

7. Prasad N, Newbern EC, Trenholme AA, Wood T, Thompson MG, Aminisani N, et al. Respiratory syncytial virus hospitalisations among young children: a data linkage study. Epidemiol Infect. 2019;147:e246. https:/ / doi.org/10.1017/S0950268819001377

8. Rha B, Dahl RM, Moyes J, Binder AM, Tempia S, Walaza S, et al. Performance of surveillance case definitions in detecting respiratory syncytial virus infection among young children hospitalized with severe respiratory illness-South Africa, 2009-2014. J Pediatric Infect Dis Soc. 2019;8:325-33. https://doi.org/10.1093/jpids/piy055

Address for correspondence: Lisa Staadegaard, Nivel, Otterstraat 118, 3513 CR Utrecht, the Netherlands; email: 1.staadegaard@nivel.nl

\section{Novel SARS-CoV-2 Variant Derived from Clade 19B, France}

\author{
Slim Fourati, Jean-Winoc Decousser, Souraya \\ Khouider, Melissa N'Debi, Vanessa Demontant, \\ Elisabeth Trawinski, Aurélie Gourgeon, Christine \\ Gangloff, Grégory Destras, Antonin Bal, Laurence \\ Josset, Alexandre Soulier, Yannick Costa, Guillaume \\ Gricourt, Bruno Lina, Raphaël Lepeule, Jean-Michel \\ Pawlotsky, Christophe Rodriguez
}

Author affiliations: Institut Mondor de Recherche Biomédicale, Université Paris-Est, Créteil, France; (S. Fourati, S. Khouider, A. Gourgeon, A. Soulier, J.-M. Pawlotsky, C. Rodriguez); Hôpital Henri Mondor, Créteil (J.-W. Decousser, M. N'Debi, V. Demontant, E. Trawinski, G. Gricourt, R. Lepeule, C. Rodriguez); Hôpital Albert Chenevier, Créteil (C. Gangloff); Université de Lyon, France (G. Destras, A. Bal, L. Josset, B. Lina); Grand Hôpital de l'Est Francilien, Jossigny, France (Y. Costa)

DOI: https://doi.org/10.3201/eid2705.210324

We report a novel severe acute respiratory syndrome coronavirus 2 variant derived from clade 19B (HMN.19B variant or Henri Mondor variant). This variant is characterized by the presence of 18 amino acid substitutions, including 7-8 substitutions in the spike protein and 2 deletions. These variants actively circulate in different regions of France.

$\mathrm{D}$ uring fall 2020, new severe acute respiratory syndrome coronavirus 2 (SARS-CoV-2) variants, some of which have become variants of concern, progressively replaced the original strains in regions 